\title{
The diet-induced metabolic syndrome is accompanied by whole-genome epigenetic changes
}

\author{
Irais Sánchez $^{1} \cdot$ Rosalia Reynoso-Camacho $^{2} \cdot$ Luis M. Salgado $^{1}$ (1)
}

Received: 12 March 2015 / Accepted: 9 May 2015/Published online: 22 May 2015

(C) Springer-Verlag Berlin Heidelberg 2015

\begin{abstract}
Consuming a high-fat/high-fructose diet (HFD) starting at a young age leads to the development of obesity and to the progression of metabolic syndrome (MS). We are interested in the relationship between MS and DNA methylation as a mediator of the metabolic memory and the early appearance of these diseases in the progeny. To this end, Wistar rats were fed a HFD for 1 year, and every 12 weeks, biochemical analyses were performed. After 24 weeks, animals fed the HFD showed alterations related to MS such as elevated blood levels of fasting glucose, triglycerides, and insulin compared with their littermate controls. During the experimental period, the control females exhibited a $40 \%$ lower 5-methylcytosine (5-mC) level compared to the control males. The HFD affected the 5 -mC levels in males and females differently. The HFD induced a $20 \%$ decrease in the 5 -mC levels in males and a $15 \%$ increase in females. We found that the HFD induces an early presentation of MS in the progeny of treated animals and that the DNA methylation was altered in the $F_{1}$ generation. The presentation of MS is positively associated with changes in the global percentage of 5-mC in the DNA.
\end{abstract}

Keywords High-fat/high-fructose diet · Metabolic syndrome $\cdot$ Epigenetic modifications $\cdot$ DNA methylation

Luis M. Salgado

luism.salgado@yahoo.com.mx

1 CICATA-IPN, CICATA-QRO, National Polytecnic Institute, Cerro Blanco No. 141, Col. Colinas del Cimatario CP, 76090 Queretaro, QRO, Mexico

2 DIPA, Faculty of Chemistry, Autonomous University of Queretaro, Cerro de las Campanas S/N., 76010 Queretaro, Mexico

\section{Introduction}

Overweight and obesity are caused by excessive fat accumulation due to changes in lifestyle and a diet rich in carbohydrates and fat, in addition to inherited genetic factors (Gupta et al. 2013; Yang et al. 2012). Those who are overweight have a high risk of developing chronic degenerative diseases such as type 2 diabetes mellitus (T2D), cancer, Alzheimer disease, or cardiovascular diseases (CVD) (Altunkaynak and Ozbek 2009; Dulloo and Montani 2012). A common link between these diseases is that their progress is led by metabolic syndrome (MS). Approximately $20-25 \%$ of the world's adult population has MS associated with obesity, which doubles their mortality rate (Yang et al. 2012).

The longer hyperglycemia is left untreated, the greater is the damage that occurs to the organs and tissues (Jax 2010), which is difficult to reverse due to metabolic memory (Ceriello et al. 2009; El-Osta 2012). Metabolic memory is initiated by a hyperglycemic state, which is remembered in target organs even after achieving glucose control (Ceriello et al. 2009; Jax 2010; Tonna et al. 2010), and as a consequence, oxidative stress induces epigenetic changes (Ceriello 2010; El-Osta et al. 2008).

Methylation in coding regions is a key mechanism of epigenetic regulation modifying gene expression without affecting the primary DNA sequence (Luttmer et al. 2013). Obesity, MS, and insulin resistance (IR) are associated with changes in DNA methylation (Gemma et al. 2010; Luttmer et al. 2013; Wang et al. 2010). Diet is a critical modulator of epigenetic programming in MS (Chaudhary et al. 2012; Pelizzola and Ecker 2011), and consumption of a high-fat diet has a strong effect on the methylation status of genes related to obesity (Milagro et al. 2013). Epigenetic changes in early postnatal life increase the susceptibility to 
developing T2D and CVD in the later stages of life (Chaudhary et al. 2012). To add to our knowledge of the relationship between DNA methylation and obesity and metabolic syndrome, specifically during its development, we used an animal model of diet-induced obesity and followed the amount of DNA methylation over time in both parental and $F_{1}$ generations.

\section{Materials and methods}

\section{Animals and experimental design}

The parental group consisted of Wistar rats obtained as weanlings from Charles River. They were adapted 1 week to the housing conditions $\left(24 \pm 1{ }^{\circ} \mathrm{C}, 12\right.$-h: 12 -h light:dark cycle $)$ in stainless steel cages $(40 \times 24 \times 19 \mathrm{~cm}$, three animals per cage) with access to food and water ad libitum. They were divided into two groups of males $(\mathrm{M})$ and females (F) fed a control diet (M-CON, $n=18$; F-CON, $n=17$ ) or a high-fat/high-fructose diet (M-HFD, $n=20$; F-HFD, $n=20$ ). The control diet was nu3Lab22-5 ${ }^{\circledR}$ (global research solution) containing $22 \%$ protein, $5 \%$ lipid ( $1 \%$ saturated fat), and $51 \%$ carbohydrate, $2.55 \%$ minerals, and $0.19 \%$ vitamins; the high-fat/high-fructose diet (HFD) was prepared supplementing $70.2 \mathrm{~g}$ nu3Lab22$5^{\circledR}$ with $14.8 \mathrm{~g}$ of commercial pork lard and $15 \mathrm{~g}$ of fructose [14.1\% protein, $37.62 \%$ lipid (17.30\% saturated fat, $3.76 \%$ linoleic acid), $46.39 \%$ carbohydrate $(32.33 \%$ fructose), $1.76 \%$ minerals, and $0.13 \%$ vitamins]. The diets were administered throughout 48 weeks. Biochemical parameters were measured at 12, 24, 36, and 48 weeks.

At weeks 24, 36, and 48, three cross breedings were set: (1) Male $_{\mathrm{HFD}} \times$ Female $_{\mathrm{HFD}}$, (2) Male $_{\mathrm{HFD}} \times$ Female $_{\mathrm{CON}}$, and (3) Male $_{\mathrm{CON}} \times$ Female $_{\mathrm{HFD}}$ (four crosses of each, one male and two females for each cross), to obtain three groups of $F_{1}$ offspring. Crosses between animals under control diet were not set because it was expected that their $F_{1}$ showed the same biochemical values as the original population. The newborn animals remained with their mothers until weaning ( 3 weeks of age), and then, the $F_{1}$ generation was randomly divided into two groups (CON and HFD) to receive the diets described above. Their biochemical parameters were measured at 12 and 24 weeks.

The diabetic group consisted of male Wistar rats $(425 \pm 11.90 \mathrm{~g}, n=4)$ that received a single dose of $45 \mathrm{mg} / \mathrm{kg}$ of streptozotocin (STZ, Sigma No. 242-646-8, dissolved in $0.05 \mathrm{M}$ citrate buffer, $\mathrm{pH} 4$ ) intraperitoneally under fasting conditions, and animals with values above $11.10 \mathrm{mmol} / \mathrm{L}$ were included in the study. The experimental procedures were in accordance with the Animal Care and Use protocol of the University of Queretaro.

\section{Measurements and blood sampling}

Tail vein blood samples were tested for fasting glucose (Accucheck Performa ${ }^{\circledR}$, Roche) and triglycerides (Accutrend Plus ${ }^{\circledR}$, Roche). The insulin concentration was measured using a commercial rat kit (EZRMI-13 $\mathrm{K}^{\circledR}$, Millipore). The IR index was calculated using the Homeostasis Model Assessment: insulin resistance (HOMA IR) according to the following equation:

[Insulin level $(\square \mathrm{U} / \mathrm{mL})$

* fasting glucose $(\mathrm{mmol} / \mathrm{L})] / 22.5$

Glucose tolerance test (GTT) A tail vein blood sample was taken at time 0 , before the glucose injection was given (the animals received an ip injection of glucose, $4 \mathrm{~mL} / \mathrm{kg}$ body weight of a $50 \%$ glucose solution), and circulating glucose levels were determined from tail vein blood samples after 30, 60, and 120 min following the injection (Alarcon-Aguilar et al. 2003).

\section{Definitions of the body mass index and metabolic syndrome}

Definition of the body mass index (BMI) in rats- 6-monthold animals were chosen as a reference to establish the BMI scale for each gender: the average body weight in kilograms and the length (measured from the tip of the nose to the base of the tail) in meters, according to the formula: BMI $=$ weight/(length $)^{2}$; the upper value for a normal BMI for males was established at 7.8 and for females at $6.7 \mathrm{~kg} /$ $\mathrm{m}^{2}$, which we estimated to be equivalent to the cutoff point of $25 \mathrm{~kg} / \mathrm{m}^{2}$ used for humans.

\section{Definition of metabolic syndrome (MS) in rats}

We took the average of the biochemical values from sixmonth-old animals, the healthy biochemical parameters considered were fasting glucose up to $5.55 \mathrm{mmol} / \mathrm{L}$, postprandial glucose up to $8.33 \mathrm{mmol} / \mathrm{L}$ after $120 \mathrm{~min}$, triglycerides up to $1.29 \mathrm{mmol} / \mathrm{L}$, and insulin approximately $262 \mathrm{pmol} / \mathrm{L}$ (males) or $168 \mathrm{pmol} / \mathrm{L}$ (females). The animals with two or three values beyond the cutoff points plus an elevated BMI were classified as having MS.

\section{Quantitation of global DNA methylation}

The DNA from blood cells was isolated according to Casabianca et al. (2007) with some modifications. The percentage of global DNA methylation was determined with a 5-mC DNA ELISA $\mathrm{Kit}^{\circledR}{ }^{\circledR}$ (Zymo Research) at $405 \mathrm{~nm}$ according to the manufacturer's instructions using 100 ng of genomic DNA. 


\section{Statistical methods}

The results are expressed as the mean \pm SEM. The difference between the HFD and CON groups was determined using Dunnett's test, with statistical significance set at $P<0.05$. Linear regression analyses were performed to follow the changes in the percentage of 5-mC over time. Analyses were performed using JMP version 10 .

\section{Results}

\section{The HFD effectively increases body weight and BMI}

The ingestion of a high-calorie diet is considered to be the leading cause of the worldwide obesity epidemic. The degree of obesity is related not only to the increase in energy consumption but to the energy density and the type and amount of fat in the diet (Westerterp-Plantenga 2001), and for this reason, we included pork lard in the HFD as the main source of saturated fat (National Research Council 1976). The ingestion of artificially sweetened beverages is another causal agent for obesity, mostly due to their fructose content. Therefore, the carbohydrate content of the experimental diet was increased with fructose.

The diets were administered throughout 48 weeks to the animals, and their body weights were measured weekly. The animals fed the HFD increased their weights faster than the control group, and they were the heaviest at the end of the experiment (Table 1). At week 36, the HFD males increased their weight approximately tenfold (compared to their weight at the beginning of the experiment), by approximately $100 \mathrm{~g}$ more than the control group of the same age. At the same time, the HFD females had increased their weight sevenfold (compared to their weight at the beginning of the experiment), by approximately $50 \mathrm{~g}$ more than their controls.

The BMI was used in this study to estimate the degree of obesity of the animals using the following upper limits: 9 and 10.3 (for overweight and obesity type II) for males, and 7.9 and 8.9 for females. The males fed the HFD were classified as overweight from week 24 onward. Some animals were classified as obesity type II, but they did not complete the 48 weeks (the heaviest animals were killed earlier). The females from the HFD group were always heavier than their controls, but both were under the established limit for a normal BMI (Table 1). The male control group was overweight from week 36 onward, probably due to the absence of physical activity of the animals in their small cages $\left(0.1 \mathrm{~m}^{2}\right.$ for two or three animals). At week 48 , the number of animals remaining was small, and we decided not to include their results, which is why the results in the tables and figures only show data up to week 36 .

\section{Development of metabolic syndrome}

Obesity has been linked to the development and severity of different pathologies including T2D, CVD, and cancer. Obesity is the main factor responsible for the problems associated with adult-onset metabolic diseases such as glucose intolerance, insulin resistance, dyslipidemia, and later type 2 diabetes and cardiovascular disorders (Liu et al. 2013; Ng et al. 2010; Schwenk et al. 2013). In addition to the change in the body weight of the animals, several biochemical parameters were measured during the experimental period to define the time frame for the development of metabolic syndrome. Increased circulating levels of glucose are considered one of the first manifestations of metabolic syndrome, and we measured fasting glucose levels in the animals every 3 months. Those fed the HFD showed higher levels of fasting glucose compared to the $\mathrm{CON}$ group throughout the experimental period, and we found significant differences from 12 weeks onward $(P<0.05$; Table 1$)$. The HFD males showed prediabetic levels from week 36 onward, while the corresponding females showed them from week 12 and on. The corresponding controls were mostly below the normal limit cutoff point.

Goumenos et al. (2002) found that fasting glucose is not the best test to detect glucose intolerance. To complete the characterization, the GTT was performed on the animals every 3 months. Glucose intolerance was markedly detected in the male HFD rats from week 24 onward, but the control males maintained normal postprandial levels throughout the study. The females did not show abnormal glucose levels during any of the sampling times (Table 1).

Glucose intolerance is a common condition that occurs in overweight or obese individuals and is accompanied by increased insulin secretion from the pancreas in an attempt to regulate the high glucose levels. This effect is known as compensatory hyperinsulinemia (Wilcox 2005). Similarly, hyperinsulinemia can be generated by the excessive consumption of fat and increased plasma-free fatty acids (Han et al. 2008). In agreement with the results from the postprandial glucose levels, the males in the HFD group showed higher insulin levels, which created a hyperinsulinemic state from week 24 onward. The other groups showed normal insulin levels throughout the experimental period, and only HFD females showed elevated levels after 36 weeks (Table 1). Subsequently, IR was determined using the HOMA index, and again, only the males fed the HFD showed high HOMA values from week 24 onward, indicating that they developed IR. All of the other groups 
Table 1 Changes in the physical and biochemical parameters for the $\mathrm{F}_{0}$ generation receiving control diet or HFD

\begin{tabular}{|c|c|c|c|c|c|c|c|}
\hline & \multicolumn{2}{|l|}{12 (weeks) } & \multicolumn{2}{|l|}{24 (weeks) } & \multicolumn{3}{|l|}{36 (weeks) } \\
\hline & CON diet & HFD & CON diet & HFD & $\mathrm{CON}$ diet & HFD & STZ \\
\hline \multicolumn{8}{|l|}{ Male } \\
\hline$n$ & 18 & 20 & 18 & 19 & 15 & 19 & 4 \\
\hline Body weight (g) & $401 \pm 8.32$ & $423 \pm 11.46$ & $521 \pm 10.20$ & $591 \pm 18.89 *$ & $606 \pm 13.06$ & $721 \pm 26.24 *$ & $425 \pm 11.90$ \\
\hline BMI $\left(\mathrm{kg} / \mathrm{m}^{2}\right)$ & $6.20 \pm 0.07$ & $6.29 \pm 0.12$ & $6.83 \pm 0.09$ & $7.49 \pm 0.18^{*}$ & $7.89 \pm 0.11$ & $9.01 \pm 0.26^{*}$ & $5.2 \pm 0.19$ \\
\hline Triglycerides (mmol/L) & $1.51 \pm 0.07$ & $1.70 \pm 0.09 *$ & $1.40 \pm 0.11$ & $1.72 \pm 0.11$ & $1.71 \pm 0.13^{*}$ & $2.52 \pm 0.18^{*}$ & $3.01 \pm 0.26$ \\
\hline Fasting glucose $(\mathrm{mmol} / \mathrm{L})$ & $4.44 \pm 0.11$ & $4.77 \pm 0.08 *$ & $4.55 \pm 0.13$ & $4.88 \pm 0.08$ & $5.50 \pm 0.19^{*}$ & $6.16 \pm 0.16^{*}$ & $21.54 \pm 0.61$ \\
\hline Postprandial glucose (mmol/L) & $7.22 \pm 0.40$ & $9.27 \pm 0.89$ & $6.38 \pm 0.23$ & $7.77 \pm 0.36^{*}$ & $7.33 \pm 0.21$ & $9.66 \pm 0.40^{*}$ & - \\
\hline Insulin $(\mathrm{pmol} / \mathrm{L})$ & $215 \pm 19$ & $294 \pm 79$ & $262 \pm 31$ & $489 \pm 37^{*}$ & $271 \pm 37$ & $518 \pm 45^{*}$ & $101 \pm 22$ \\
\hline HOMA IR & $9.41 \pm 0.85$ & $9.07 \pm 0.63$ & $10.45 \pm 1.15$ & $17.65 \pm 4.35$ & $10.63 \pm 1.73$ & $19.28 \pm 2.61^{*}$ & $15.90 \pm 3.30$ \\
\hline \multicolumn{8}{|l|}{ Female } \\
\hline$n$ & 17 & 20 & 17 & 20 & 11 & 12 & \\
\hline Body weight $(\mathrm{g})$ & $242 \pm 4.89$ & $261 \pm 5.33^{*}$ & $270 \pm 5.73$ & $305 \pm 8.96^{*}$ & $318 \pm 15.09$ & $363 \pm 20.19^{*}$ & - \\
\hline BMI $\left(\mathrm{kg} / \mathrm{m}^{2}\right)$ & $5.12 \pm 0.08$ & $5.39 \pm 0.08 *$ & $5.18 \pm 0.08$ & $5.64 \pm 0.13^{*}$ & $5.96 \pm 0.20$ & $6.57 \pm 0.29$ & - \\
\hline Triglycerides (mmol/L) & $1.16 \pm 0.13$ & $1.29 \pm 0.10$ & $1.71 \pm 0.07$ & $1.53 \pm 0.06$ & $1.60 \pm 0.06$ & $1.68 \pm 0.09$ & - \\
\hline Fasting glucose $(\mathrm{mmol} / \mathrm{L})$ & $4.83 \pm 0.17$ & $5.61 \pm 0.26^{*}$ & $4.88 \pm 0.15$ & $5.50 \pm 0.13^{*}$ & $5.61 \pm 0.35$ & $6.33 \pm 0.47$ & - \\
\hline Postprandial glucose (mmol/L) & $6.66 \pm 0.23$ & $7.49 \pm 0.44$ & $5.72 \pm 0.09$ & $5.94 \pm 0.12$ & $7.11 \pm 0.35$ & $7.72 \pm 0.35$ & - \\
\hline Insulin $(\mathrm{pmol} / \mathrm{L})$ & $129 \pm 16$ & $121 \pm 15$ & $168 \pm 38$ & $243 \pm 66$ & $209 \pm 22$ & $285 \pm 15^{*}$ & - \\
\hline HOMA IR & $5.48 \pm 0.80$ & $4.96 \pm 0.99$ & $7.26 \pm 1.99$ & $7.96 \pm 1.34$ & $9.11 \pm 1.36$ & $13.18 \pm 1.42 *$ & - \\
\hline
\end{tabular}

All results were expressed as mean \pm SEM

CON diet control diet, HFD high-fat/high-fructose diet, STZ streptozotocin, BMI body mass index, HOMA IR Homeostasis Model Assessment: insulin resistance

Mean values differ significantly from the control, $* P<0.05$, tested by Dunnett's test

had normal HOMA values and did not develop IR (Table 1).

A direct consequence of a HFD is a high level of circulating triglycerides, and their elevation is one important feature of metabolic syndrome. The males in the HFD group showed the highest levels of triglycerides among the four groups, and it was significant from week 12 on $(P<0.05)$. Their triglyceride levels reached a maximum at week 36 (Table 1) and were maintained up to week 48 (data not shown). The females in the CON and HFD groups did not show a significant difference at any time point, but there was a trend for the triglyceride levels to be higher in the HFD group compared to the CON group (Table 1).

The animals fed the HFD showed, throughout the experiment, alterations in their biochemical parameters that resembled those that are present during MS in humans. Using the criteria established in the previous section, MS development was observed in both genders. The first animals fulfilling the requirements to be classified as having MS came from the HFD female group (Fig. 1a). After 36 weeks, an increasing number of animals, nearly $40 \%$ of males and females, were classified as having MS. At this time, even some animals under the control diet showed characteristics of MS (Fig. 1a), we believe that this should be a consequence of their increase in weight due to their lack of movement as mentioned before. The number of animals with MS was almost the same in the four groups after 48 weeks, although the cumulative number of animals with MS was around $90 \%$ for those receiving the HFD (data not shown).

\section{DNA methylation and metabolic syndrome}

Different mechanisms have been proposed to explain the deleterious effects of hyperglycemia (Brownlee 2005; Zhang et al. 2012). Among them, epigenetic modifications are a notable mechanism to explain the damage caused by the high glucose levels and its long-lasting effects (Liu et al. 2013; Schwenk et al. 2013). From peripheral blood leukocytes, we isolated DNA and measured the percentage of global methylation (percentage of 5-methylcytosine, 5 -mC). The percentage of methylated DNA from control animals at week 12 was $2.14 \%$ for males and $1.27 \%$ for females (Table 2) that are values that are in the range of previously published data (Crescenti et al. 2013; Shimabukuro et al. 2006). The percentage of methylation increased with time, and although the differences were not significant, the trend is evident from the regression line plotted from the values in Table 2, which gave $R^{2}$ values of 0.95 and 0.93 for males and females, respectively (Fig. 2a, 
b). The HFD induced changes in the percentage of DNA methylation, but males and females were affected differently (Table 2): In males, the diet induced a reduction in the amount of methylation to $1.69 \%$ at week 12 , and the values, which increased over time, were always lower than in their controls (Table 2; Fig. 2a). In the females, the HFD induced an increase in the amount of methylation to $1.48 \%$, and the values were higher than in their controls (Table 2; Fig. 2b). Similar to the results obtained with the controls, males and females fed the HFD showed an
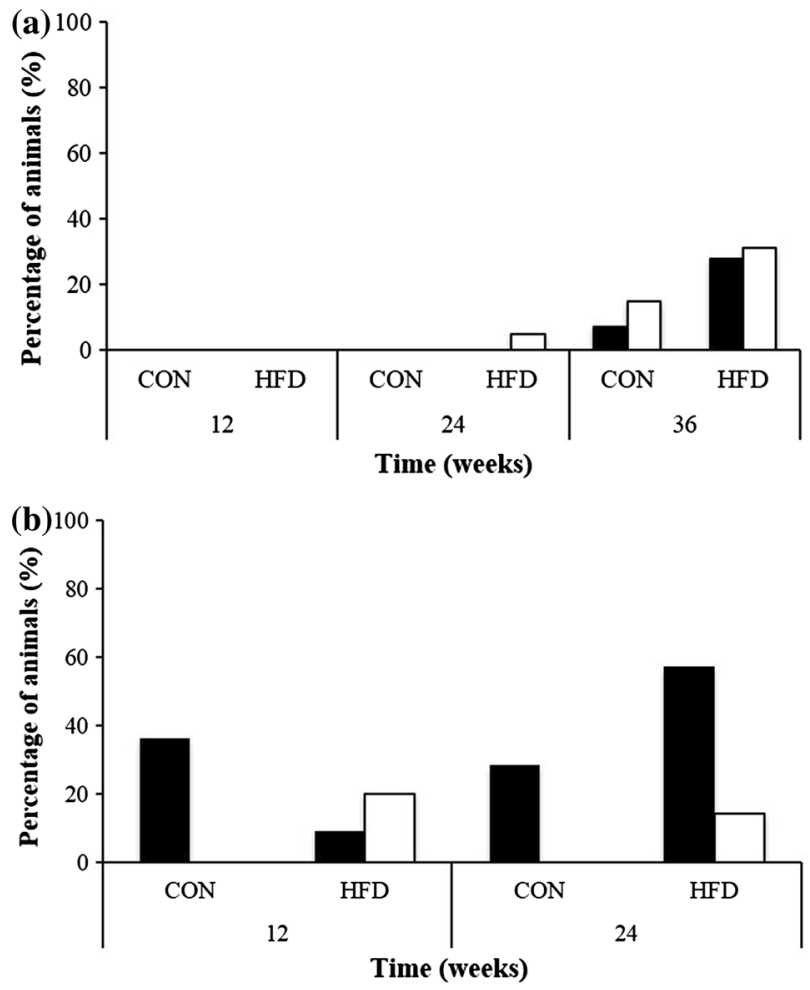

Fig. 1 Percentage of animals with metabolic syndrome. The percentage of animals fed with high-fat/high-fructose diet (HFD) or control diet $(\mathrm{CON})$ that developing $\mathrm{MS} \mathbf{a} \mathrm{F}_{0}$ and $\mathbf{b} \mathrm{F}_{1}$ generation. The black bars represent males and white bars females increase in their percentage of DNA methylation over time, and the $R^{2}$ values for males and females were 0.99 and 0.91 , respectively.

Diabetic animals, as induced by STZ, were used for comparison. In Table 1, some of their biochemical parameters are shown; one observes high levels of glucose and triglycerides that characterize their health status. In Table 2, the amount of methylated DNA reached $2.89 \%$, a number higher than any of those obtained with the other experimental groups, either under the control or HFD.

\section{Transmission of metabolic syndrome to the offspring}

Recent studies have suggested that environmentally induced epigenetic modifications may be transmissible through the germline and may be an important mechanism underlying intergenerational effects (King et al. 2013). Changes in gene expression related to energy metabolism and DNA methylation indicate that a high risk of developing MS might originate during the intrauterine growth period (Lin et al. 2012) and may be transmissible through the germline (King et al. 2013). We performed three types of crosses to obtain the offspring involving at least one parent under the HFD. In general, more male than female offspring were produced for the different crosses and mating times, and the oldest parents produced the lowest number of offspring. The results shown correspond to crosses obtained from the parental animals aged 24 and 36 weeks old because crosses initiated with 48-week-old animals did not produce progeny. The cross set with animals 24 weeks old produced a progeny of $29\left(\mathrm{M}_{\mathrm{HFD}} \times-\right.$ $\left.\mathrm{F}_{\mathrm{HFD}}, 3 ; \mathrm{M}_{\mathrm{HFD}} \times \mathrm{F}_{\mathrm{CON}} 8 ; \mathrm{M}_{\mathrm{CON}} \times \mathrm{F}_{\mathrm{HFD}}, 18\right), 18$ males and 11 females, while from the cross set with animals 36 weeks old produced a progeny of seven $\left(\mathrm{M}_{\mathrm{CON}} \times \mathrm{F}_{\mathrm{HFD}}\right.$, 7), four males and three females. The progeny were classified according to their origin and maintained with their littermates receiving the same diet. Some crosses gave only

Table 2 Global DNA methylation of the DNA in the $\mathrm{F}_{0}$ generation measured from peripheral blood leukocytes at different time points

\begin{tabular}{|c|c|c|c|c|c|c|c|}
\hline & \multicolumn{2}{|l|}{12 (weeks) } & \multicolumn{2}{|l|}{24 (weeks) } & \multicolumn{3}{|l|}{36 (weeks) } \\
\hline & $\mathrm{CON}$ diet & HFD & $\mathrm{CON}$ diet & HFD & $\mathrm{CON}$ diet & HFD & STZ \\
\hline \multicolumn{8}{|l|}{ Male } \\
\hline$n$ & 3 & 3 & 4 & 3 & 3 & 5 & 4 \\
\hline \multicolumn{7}{|l|}{ Female } & $2.89 \pm 0.07$ \\
\hline$n$ & 4 & 6 & 4 & 5 & 3 & 5 & \\
\hline$\%$ 5-mC in blood & $1.27 \pm 0.08$ & $1.48 \pm 0.05$ & $1.34 \pm 0.04$ & $1.52 \pm 0.11$ & $1.53 \pm 0.13$ & $1.68 \pm 0.18$ & - \\
\hline
\end{tabular}

All results were expressed as mean \pm SEM

$C O N$ diet control diet, $H F D$ high-fat/high-fructose diet, $S T Z$ streptozotocin, 5-mC 5-methylcytosine

Mean values significantly differ from the control, $* P<0.05$, tested by Dunnett's test 

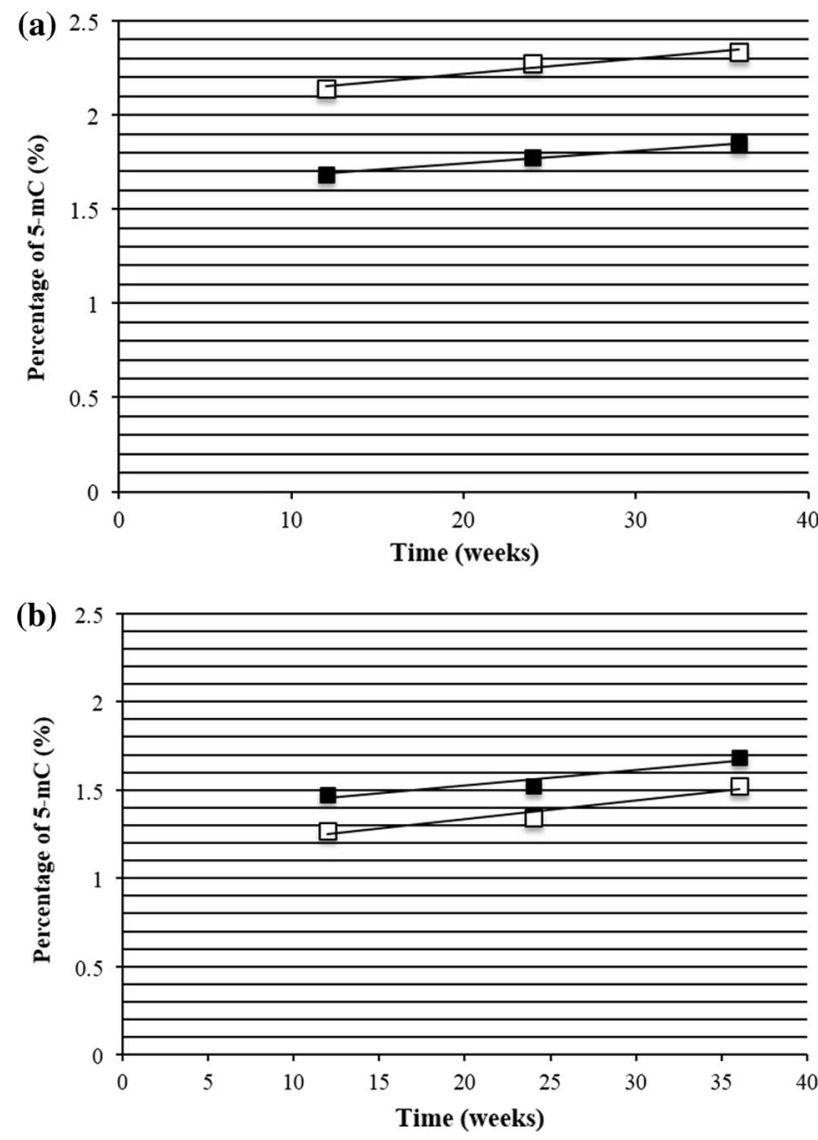

Fig. 2 Linear regression of 5-mC. a Male and b female of $\mathrm{F}_{0}$ generation. The black represents high-fat/high-fructose diet (HFD) and white control diet $(\mathrm{CON})$. Male $\mathrm{F}_{0} \mathrm{CON}$ : $\mathrm{y}=0.0081 \mathrm{x}+2.054$ $R^{2}=0.95316$ HFD: $\mathrm{y}=0.0067 \mathrm{x}+1.6083, R^{2}=0.99705$

two or three animals, and they were assigned to the HFD group; if more siblings were available, some were assigned to the control-diet group (Table 3).

The same biochemical parameters measured in the parental generation were used to characterize their progeny. We found that the $F_{1}$ generation, regardless of the type of diet, had higher biochemical parameters compared to the $\mathrm{F}_{0}$ generation (Table $3 \mathrm{a}, \mathrm{b}$ ), and the $\mathrm{F}_{1}$ animals fed the HFD showed the highest values. The quantities obtained from the males at week 12 were comparable, independent of the diet (Table 3a). However, at week 24, the effect of the HFD exacerbated the measured parameters (Table 3b). The females showed similar values at week 12 , and the HFD worsened only some parameters (such as postprandial glucose) after 12 weeks more.

Starting at week 12, the elevated levels of circulating glucose and triglycerides, among the other changes, suggested that MS was present in the animals of the $F_{1}$ generation. We found that MS develops after week 12 in animals of the $F_{1}$ generation almost independent of diet. We did not have any $\mathrm{F}_{1}$-CON female animals developing MS (Fig. 1b). At week 24, more animals were diagnosed with MS, and again, females fed the control diet did not have MS (Fig. 1b). These results demonstrated early alterations in the biochemical parameters and the presentation of MS at early ages in the progeny of animals fed a HFD.

Finally, from whole blood, we estimated the percentage of 5-mC in the DNA of the $F_{1}$ generation. The $F_{1}$ males fed with HFD showed similar percentages of 5-mC than those of the $\mathrm{F}_{0}$ control generation at the same age at the two time points tested, 12 and 24 weeks (Table 4). The $F_{1}$ males fed the control diet showed a trend to lower percentages of 5-mC than those of the control $\mathrm{F}_{0}$. The $\mathrm{F}_{1}$ females showed higher values than their $F_{0}$ control generation at 12 weeks, independent of the diet, but showed similar values at week 24, as well, independent of the diet (Table 4).

A positive association between MS and the percentage of 5-mC was found, and this association is greater in males than in females (Table 5). This strong association suggests that changes in the percentage of $5-\mathrm{mC}$ in the $\mathrm{F}_{1}$ generation compared to the $\mathrm{F}_{0} \mathrm{CON}$ group occur due to the presence of MS.

\section{Discussion}

The experimental diet given to the animals was enriched in saturated fats and fructose to simulate the composition and caloric intake consumed by population in developed countries. This type of diet alters several biochemical parameters, and therefore, it is considered the principal cause of the obesity epidemic (Buettner et al. 2007; Pham and Lee 2012; Yang et al. 2012; Yang and Huffman 2013). The animals fed the HFD showed metabolic alterations starting at week 12 and fully developed alterations at week 24 . At this stage, the metabolic alterations led to a positive diagnosis for MS in some animals, and the number of affected animals increased over time. The HFD male group had the highest values of the biochemical parameters, but there were not a significantly higher number of animals in the HFD male group with MS compared to the corresponding female group. The results we presented completely agree with the hypothesis that explains the increase in the number of overweight individuals worldwide not only by the increase in caloric ingestion but also by the increased amount of saturated fat and fructose in their diets.

We showed that even when the animals received a healthy and balanced diet, a lack of physical activity results in the animals becoming overweight and increasing their risk of developing MS. As stated before, the male control group was overweight from week 36 onward, possibly due to the absence of physical activity of the animals in their small cages. The size of the cages $\left(0.1 \mathrm{~m}^{2}\right.$ for two or three animals) did not allow the movement of the rats, they move 


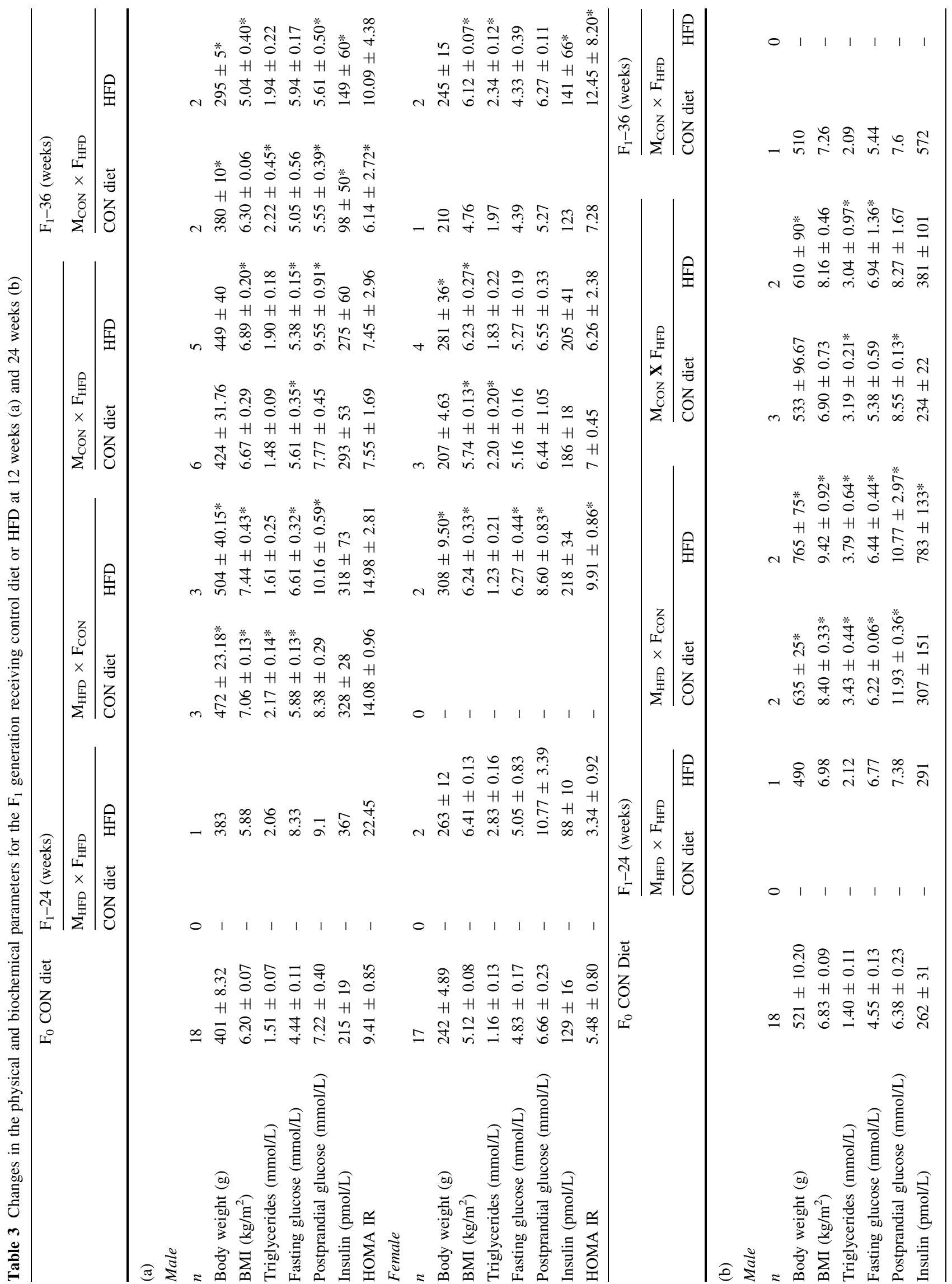




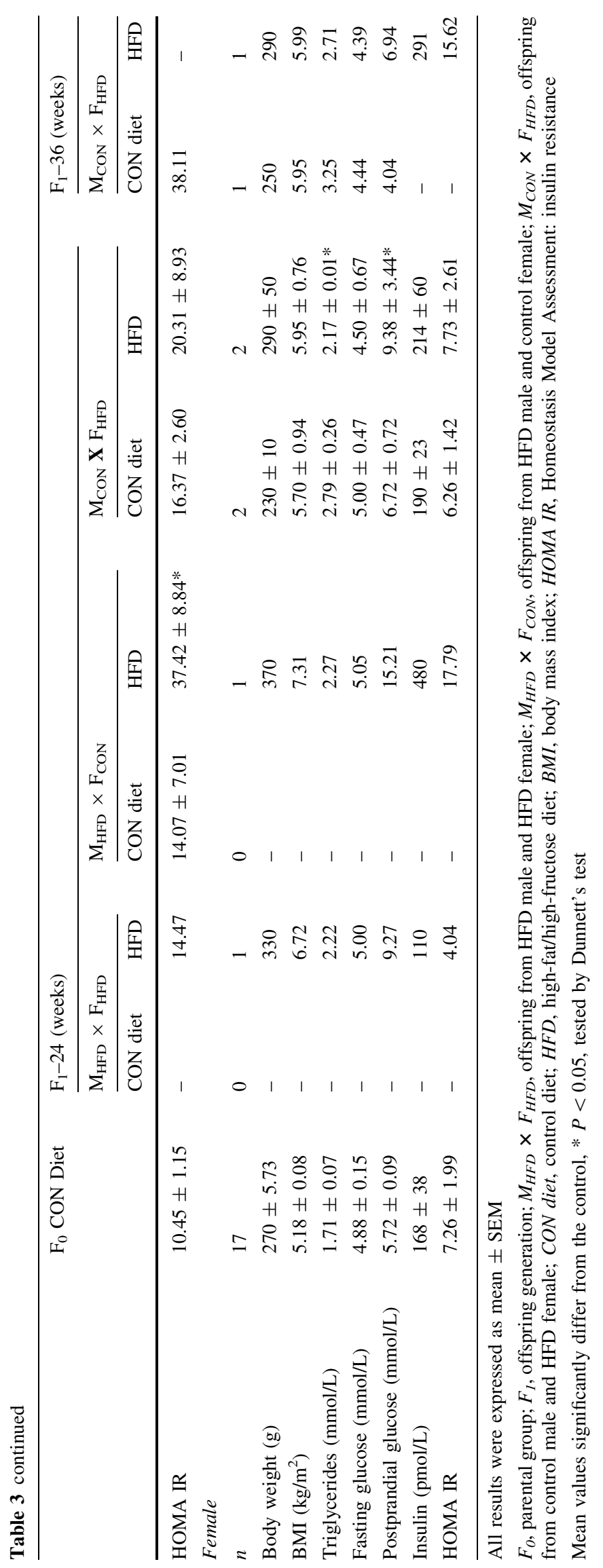


Table 4 Global DNA methylation of the DNA in the $\mathrm{F}_{1}$ generation measured from peripheral blood leukocytes at 12 weeks and 24 weeks

\begin{tabular}{|c|c|c|c|c|c|c|}
\hline & \multicolumn{3}{|l|}{12 (weeks) } & \multicolumn{3}{|l|}{24 (weeks) } \\
\hline & $\mathrm{F}_{0} \mathrm{CON}$ diet & $\mathrm{CON}$ diet & $\mathrm{F}_{1} \mathrm{HFD}$ & $\mathrm{F}_{0} \mathrm{CON}$ diet & $\mathrm{CON}$ diet & $\mathrm{F}_{1} \mathrm{HFD}$ \\
\hline \multicolumn{7}{|l|}{ Male } \\
\hline$n$ & 3 & 2 & 2 & 4 & 4 & 4 \\
\hline$\%$ 5-mC in blood & $2.14 \pm 0.10$ & $1.87 \pm 0.16$ & $2.14 \pm 0.51$ & $2.27 \pm 0.39$ & $2.14 \pm 0.21$ & $2.30 \pm 0.32$ \\
\hline \multicolumn{7}{|l|}{ Female } \\
\hline$n$ & 4 & 1 & 3 & 4 & 2 & 2 \\
\hline$\% 5-\mathrm{mC}$ in blood & $1.27 \pm 0.08$ & 1.64 & $1.39 \pm 0.02$ & $1.34 \pm 0.04$ & $1.33 \pm 0.01$ & $1.32 \pm 0.04$ \\
\hline
\end{tabular}

All results were expressed as mean \pm SEM

$F_{O} C O N$ diet, parental group with control diet; $F_{1}$, offspring generation; $C O N$ diet control diet; HFD high-fat/high-fructose diet; 5- $m C$ 5-methylcytosine

Mean values significantly differ from the control, $* P<0.05$, tested by Dunnett's test

Table 5 Association between metabolic syndrome versus percentage of 5-methylcytosine in rats

\begin{tabular}{|c|c|c|c|c|c|c|c|c|c|}
\hline \multicolumn{5}{|l|}{ Male } & \multicolumn{5}{|l|}{ Female } \\
\hline $\begin{array}{l}\text { Time } \\
\text { (weeks) }\end{array}$ & $\begin{array}{l}\text { Dependent } \\
\text { variable }\end{array}$ & $\begin{array}{l}\text { Independent } \\
\text { variable }\end{array}$ & Estimates & $P$ value & $\begin{array}{l}\text { Time } \\
\text { (weeks) }\end{array}$ & $\begin{array}{l}\text { Dependent } \\
\text { variable }\end{array}$ & $\begin{array}{l}\text { Independent } \\
\text { variable }\end{array}$ & Estimates & $P$ value \\
\hline \multicolumn{10}{|l|}{$F_{O}$} \\
\hline 12 & $5-\mathrm{mC}$ & MS & 1.9126 & $<0.0001$ & 12 & $5-\mathrm{mC}$ & MS & 1.3932 & $<0.0001$ \\
\hline 24 & $5-\mathrm{mC}$ & MS & 2.0596 & 0.0002 & 24 & $5-\mathrm{mC}$ & MS & 3.0705 & $<0.0001$ \\
\hline 36 & $5-\mathrm{mC}$ & MS & 2.0299 & $<0.0001$ & 36 & $5-\mathrm{mC}$ & MS & 1.6238 & $<0.0001$ \\
\hline \multicolumn{10}{|l|}{$F_{1}$} \\
\hline 12 & $5-\mathrm{mC}$ & MS & 2.0623 & $<0.0001$ & 12 & $5-\mathrm{mC}$ & MS & 1.3613 & $<0.0001$ \\
\hline 24 & $5-\mathrm{mC}$ & MS & 2.2344 & $<0.0001$ & 24 & $5-\mathrm{mC}$ & MS & 1.3320 & $<0.0001$ \\
\hline
\end{tabular}

5-mC 5-methylcytosine; $F_{O}$ parental group; $F_{1}$ offspring group; $M S$ metabolic syndrome

for feeding or drinking. We believe that the animals, after reaching their maximal development, became overweight due to a lack of exercise in their restricted space. These results support the hypothesis that in addition to the increased caloric intake, the second problem is the lack of physical activity.

Acquiring full-blown MS is not necessary to develop complications such as T2D, CVD, or cancer, because alterations in one or two of the biochemical parameters are enough to initiate them. Once started, the induced damage to the organs and tissues could be irreversible, even when treated. Studies suggest that changes in the expression of genes maintained through epigenetic modifications could be the reason for this so-called metabolic memory. Environmental factors such as nutrition can affect the methylation of genes involved in glucose and lipid metabolism (Schwenk et al. 2013). Recent studies suggest that epigenetic regulation of gene expression could be a major contributor to the susceptibility to diseases such as obesity and type 2 diabetes (Liu et al. 2013; Schwenk et al. 2013).

We measured the global amount of 5-mC and determined the biochemical parameters simultaneously. The aim was to demonstrate that changes in the percentage of global methylation occur due to MS. We found different levels of methylation between the male and female controls; the percentage of 5-mC in females was approximately $40 \%$ less than the values of the littermate males. Another finding was that the HFD differentially affected the amount of 5-mC in the two genders: In males, the HFD induced a $20 \%$ decrease, and in females, the HFD induced a $15 \%$ increase. In both cases, the effect persisted until the end of the experiment (48 weeks). To compare our results with previous studies, Gallou-Kabani et al. (2010) demonstrated that consumption of a HFD has an effect on the percentage of global DNA methylation only in females, but we found changes in both genders. Other authors have shown that an increase in the levels of some biochemical parameters is related to changes in DNA methylation in adipose tissue, muscle, and liver (Dunn and Bale 2009; Jiang et al. 2011; Khalyfa et al. 2013; Liu et al. 2013), but they focused their studies on specific genes or genomic regions, and they did not analyze global levels of 5 -mC. We are unaware of any reports on the difference in the percentage of genomic DNA methylation due to 
gender, but our results clearly show that males have a higher percentage of $5-\mathrm{mC}$ compared to females at the same time points.

The progeny of affected parents have an increased risk of developing the disease, and they develop the disease at an earlier age than their parents did. Our data showed that $\mathrm{F}_{1}$ animals presented with $\mathrm{MS}$, or at least altered biochemical measurements, at younger ages. The progeny obtained trough the different cross set gave limited number of animals, as it shown before. Even so, their biochemical data were very homogeneous and we are confident of the implications derived from such results. Studies in animal models show that offspring of obese mothers are more susceptible to chronic conditions including obesity and cardiovascular, renal, and metabolic diseases (Henry et al. 2012). Ng et al. (2010) demonstrated that paternal consumption of a HFD-induced intergenerational alterations in the homeostasis between glucose and insulin in female offspring, and another study showed that parental exposure to a HFD may lead to increased IR in the offspring (Attig et al. 2013). There are reports of lasting effects of a high-fat diet and obesity on the progeny; they showed that even when there are changes in the glucose and insulin levels in animals of the $F_{1}$ generation, the type of diet has an effect on the $\mathrm{F}_{2}$ generation (Fullston et al. 2013; King et al. 2013).

We demonstrated that the HFD induces an early presentation of MS in the progeny of treated animals, and the methylation of their DNA was altered in this $F_{1}$ generation. Once more, the number of the animals was not enough to perform a better statistical analysis of the data. The trend of the $F_{1}$ generation was to show similar amounts of 5-mC, independent of the diet. After 24 weeks, the $F_{1}$ generation has similar levels of 5-mC for the two diet groups, and the values were quite similar to those obtained from the parental $\left(\mathrm{F}_{0}\right)$ generation at the same age. We do not know whether such similarity has any health implications, but more research is needed in the future.

\section{Conclusion}

We showed that the consumption of a HFD, similar to the diet of Western countries, is sufficient to produce obesity, insulin resistance, hyperglycemia, and hypertriglyceridemia, which contribute to the development of MS. The progeny of animals which received the HFD presented abnormal biochemical parameters or MS at younger ages. The presentation of MS is positively associated with changes in the global percentage of 5-mC in the DNA.

Acknowledgments The authors thank Dr. Juan Riesgo (INBUNAM, Queretaro, Mexico) and Reynaldo Pless (CICATA-IPN, Queretaro, Mexico) for their help in the preparation of the manuscript.
IS received scholarships from CONACYT and PIFI (SIP-IPN), Mexico. The work was supported from Grants from SIP-IPN (LMS) and CONACYT (RRC).

Conflict of interest Irais Sanchez, Rosalia Reynoso-Camacho, and Luis M. Salgado declare that they have no conflict of interest.

Ethical standard All institutional and national guidelines for the care and use of laboratory animals were followed.

\section{References}

Alarcon-Aguilar FJ, Valdes-Arzate A, Xolalpa-Molina S, BanderasDorantes T, Jimenez-Estrada M, Hernandez-Galicia E, RomanRamos R (2003) Hypoglycemic activity of two polysaccharides isolated from opuntia ficus-indica and O. Streptacantha. Proc West Pharmacol Soc 46:139-142

Altunkaynak BZ, Ozbek E (2009) Overweight and structural alterations of the liver in female rats fed a high-fat diet: a stereological and histological study. Turk J Gastroenterol 20:93-103

Attig L, Vigé A, Gabory A, Karimi M, Beauger A, Gross MS, Athias A, Gallou-Kabani C, Gambert P, Ekstrom TJ, Jais JP, Junien C (2013) Dietary alleviation of maternal obesity and diabetes: increased resistance to diet-induced obesity transcriptional and epigenetic signatures. PLoS ONE 8:e66816. doi:10.1371/journal. pone. 0066816

Brownlee M (2005) The pathobiology of diabetic complications: a unifying mechanism. Diabetes 54:1615-1625. doi:10.2337/ diabetes.54.6.1615

Buettner R, Schölmerich J, Bollheimer LC (2007) High-fat diets: modeling the metabolic disorders of human obesity in rodents. Obesity 15:798-808. doi:10.1038/oby.2007.608

Casabianca A, Gori C, Orlandi C, Forbici F, Federico Perno C, Magnani M (2007) Fast and sensitive quantitative detection of HIV DNA in whole blood leucocytes by SYBR green I real-time PCR assay. Mol Cell Probes 21(5-6):368-378. doi:10.1016/j. mcp.2007.05.005

Ceriello A (2010) Hyperglycaemia and the vessel wall: the pathophysiological aspects on the atherosclerotic burden in patients with diabetes. Eur J Cardiovasc Prev Rehabil 17(Suppl 1):S15S19. doi:10.1097/01.hjr.0000368193.24732.66

Ceriello A, Ihnat MA, Thorpe JE (2009) Clinical review 2: the "metabolic memory": Is more than just tight glucose control necessary to prevent diabetic complications? J Clin Endocrinol Metab 94(2):410-415. doi:10.1210/jc.2008-1824

Chaudhary N, Nakka KK, Maulik N, Chattopadhyay S (2012) Epigenetic manifestation of metabolic syndrome and dietary management. Antioxid Redox Signal 17:254-281. doi:10.1089/ ars. 2011.4387

Crescenti A, Solà R, Valls RM, Caimari A, Del Bas JM, Anguera A, Anglés N, Arola L (2013) Cocoa consumption alters the global dna methylation of peripheral leukocytes in humans with cardiovascular disease risk factors: a randomized controlled trial. PLoS ONE 8:e65744. doi:10.1371/journal.pone.0065744

Dulloo AG, Montani JP (2012) Body composition, inflammation and thermogenesis in pathways to obesity and the metabolic syndrome: an overview. Obes Rev 13(Suppl 2):1-5. doi:10. 1111/j.1467-789X.2012.01032.x

Dunn GA, Bale TL (2009) Maternal high-fat diet promotes body length increases and insulin insensitivity in second-generation mice. Endocrinology 150:4999-5009. doi:10.1210/en.2009-0500

El-Osta A (2012) Redox mediating epigenetic changes confer metabolic memories. Circ Res 111(3):262-264. doi:10.1161/ CIRCRESAHA.112.274936 
El-Osta A, Brasacchio D, Yao D, Pocai A, Jones PL, Roeder RG, Cooper ME, Brownlee M (2008) Transient high glucose causes persistent epigenetic changes and altered gene expression during subsequent normoglycemia. J Exp Med 205(10):2409-2417. doi: $10.1084 /$ jem.20081188

Fullston T, Ohlsson Teague EM, Palmer NO, DeBlasio MJ, Mitchell M, Corbett M, Print CG, Owens JA, Lane M (2013) Paternal obesity initiates metabolic disturbances in two generations of mice with incomplete penetrance to the F2 generation and alters the transcriptional profile of testis and sperm microRNA content. FASEB J 27:4226-4243. doi:10.1096/fj.12-224048

Gallou-Kabani C, Gabory A, Tost J, Karimi M, Mayeur S, Lesage J, Boudadi E, Gross MS, Taurelle J, Vigé A, Breton C, Reusens B, Remacle C, Vieau D, Ekström TJ, Jais JP, Junien C (2010) Sexand diet-specific changes of imprinted gene expression and DNA methylation in mouse placenta under a high-fat diet. PLoS ONE 5:e14398. doi:10.1371/journal.pone.0014398

Gemma C, Sookoian S, Dieuzeide G, García SI, Gianotti TF, González CD, Pirola CJ (2010) Methylation of TFAM gene promoter in peripheral white blood cells is associated with insulin resistance in adolescents. Mol Genet Metab 100:83-87. doi:10.1016/j.ymgme.2010.02.004

Goumenos DS, Tsakas S, El-Nahas AM, Alexandri S, Oldroyd S, Kalliakmani P, Vlachojannis JG (2002) Transforming growth factor-1 in the kidney and urine of patients with glomerular disease and proteinuria. Nephrol Dial Transplant 17:2145-2152. doi:10.1093/ndt/17.12.2145

Gupta N, Shah P, Nayyar S, Misra A (2013) Childhood obesity and the metabolic syndrome in developing countries. Indian J Pediatr 80(Suppl 1):28-37. doi:10.1007/s12098-012-0923-5

Han P, Zhang YY, Lu Y, He B, Zhang W, Xia F (2008) Effects of different free fatty acids on insulin resistance in rats. Hepatobiliary Pancreat Dis Int 7:91-96

Henry SL, Barzel B, Wood-Bradley RJ, Burke SL, Head GA, Armitage JA (2012) Developmental origins of obesity-related hypertension. Clin Exp Pharmacol Physiol 39:799-806. doi:10. 1111/j.1440-1681.2011.05579.x

Jax TW (2010) Metabolic memory: a vascular perspective. Cardiovasc Diabetol 9:51. doi:10.1186/1475-2840-9-51

Jiang M, Zhang Y, Liu M, Lan MS, Fei J, Fan W, Gao X, Lu D (2011) Hypermethylation of hepatic glucokinase and L-type pyruvate kinase promoters in high-fat diet-induced obese rats. Endocrinology 152:1284-1289. doi:10.1210/en.2010-1162

Khalyfa A, Carreras A, Hakim F, Cunningham JM, Wang Y, Gozal D (2013) Effects of late gestational high-fat diet on body weight, metabolic regulation and adipokine expression in offspring. Int $\mathbf{J}$ Obes 37:1481-1489. doi:10.1038/ijo.2013.12

King V, Dakin RS, Liu L, Hadoke PW, Walker BR, Seckl JR, Norman JE, Drake AJ (2013) Maternal obesity has little effect on the immediate offspring but impacts on the next generation. Endocrinology 154:2514-2524. doi:10.1210/en.2013-1013

Lin Y, Zhuo Y, Fang ZF, Che LQ, Wu D (2012) Effect of maternal dietary energy types on placenta nutrient transporter gene expressions and intrauterine fetal growth in rats. Nutrition 28:1037-1043. doi:10.1016/j.nut.2012.01.002

Liu HW, Mahmood S, Srinivasan M, Smiraglia DJ, Patel MS (2013) Developmental programming in skeletal muscle in response to overnourishment in the immediate postnatal life in rats. J Nutr Biochem 24:1859-1869. doi:10.1016/j.jnutbio.2013.05.002

Luttmer R, Spijkerman AM, Kok RM, Jakobs C, Blom HJ, Serne EH, Dekker JM, Smulders YM (2013) Metabolic syndrome components are associated with DNA hypomethylation. Obes Res Clin Pract 7:e106-e115. doi:10.1016/j.orcp.2012.06.001

Milagro FI, Mansego ML, De Miguel C, Martínez JA (2013) Dietary factors, epigenetic modifications and obesity outcomes: progresses and perspectives. Mol Asp Med 34:782-812. doi:10. 1016/j.mam.2012.06.010

National Research Council (1976) Fat content and composition of animal products. Printing and Publishing Office. National Academy of Science, Washington, DC, p 203

Ng SF, Lin RC, Laybutt DR, Barres R, Owens JA, Morris MJ (2010) Chronic high-fat diet in fathers programs $\beta$-cell dysfunction in female rat offspring. Nature 467:963-966. doi:10.1038/ nature 09491

Pelizzola M, Ecker JR (2011) The DNA methylome. FEBS Lett 585:1994-2000. doi:10.1016/j.febslet.2010.10.061

Pham TX, Lee J (2012) Dietary regulation of histone acetylases and deacetylases for the prevention of metabolic diseases. Nutrients 4:1868-1886. doi:10.3390/nu4121868

Schwenk RW, Jonas W, Ernst SB, Kammel A, Jähnert M, Schürmann A (2013) Diet-dependent alterations of hepatic Scd1 expression are accompanied by differences in promoter methylation. Horm Metab Res 45:786-794. doi:10.1055/s-0033-1348263

Shimabukuro M, Jinno Y, Fuke C, Okazaki Y (2006) Haloperidol treatment induces tissue- and sex-specific changes in DNA methylation: a control study using rats. Behav Brain Funct 2:37. doi:10.1186/1744-9081-2-37

Tonna S, El-Osta A, Cooper ME, Tikellis C (2010) Metabolic memory and diabetic nephropathy: potential role for epigenetic mechanisms. Nat Rev Nephrol 6(6):332-341. doi:10.1038/ nrneph.2010.55

Wang X, Zhu H, Snieder H, Su S, Munn D, Harshfield G, Maria BL, Dong Y, Treiber F, Gutin B, Shi H (2010) Obesity related methylation changes in DNA of peripheral blood leukocytes. BMC Med 8:87. doi:10.1186/1741-7015-8-87

Westerterp-Plantenga MS (2001) Analysis of energy density of food in relation to energy intake regulation in human subjects. Br J Nutr 85:351-361. doi:10.1079/BJN2000272

Wilcox G (2005) Insulin and insulin resistance. Clini Biochemist Rev 26:19-39

Yang Z, Huffman SL (2013) Nutrition in pregnancy and early childhood and associations with obesity in developing countries. Matern Child Nutr 9(Suppl 1):105-119. doi:10.1111/mcn.12010

Yang ZH, Miyahara H, Takeo J, Katayama M (2012) Diet high in fat and sucrose induces rapid onset of obesity-related metabolic syndrome partly through rapid response of genes involved in lipogenesis, insulin signalling and inflammation in mice. Diabetol Metab Syndr 4:32. doi:10.1186/1758-5996-4-32

Zhang L, Chen B, Tang L (2012) Metabolic memory: mechanisms and implications for diabetic retinopathy. Diabetes Res Clin Pract 96:286-293. doi:10.1016/j.diabres.2011.12.006 